\title{
DNA from 33-year-old dried moth specimens help confirm larva as the elusive Wiseana fuliginea
}

\author{
N.K. Richards ${ }^{1}$, H. Ehau-Taumaunu ${ }^{1,2,3}$ and C.M. Ferguson ${ }^{4}$ \\ ${ }^{1}$ AgResearch, Lincoln Science Centre, Private Bag 4749, Christchurch 8140, New Zealand \\ ${ }^{2}$ School of Biological Sciences, University of Auckland, Private Bag 92019, Auckland 1142, \\ New Zealand \\ ${ }^{3}$ Bio-Protection Research Centre, Lincoln University, PO Box 85084, Canterbury 7647, New Zealand \\ ${ }^{4}$ AgResearch, Invermay Agricultural Centre, Private Bag 50034, Mosgiel 9053, New Zealand \\ Corresponding author: nicola.richards@agresearch.co.nz
}

\begin{abstract}
Caterpillars of the genus Wiseana, commonly known as porina, are pests of improved pastures in New Zealand. Seven species are currently recognised but morphological identification of individual species is extremely difficult. Therefore, two new molecular-based identification methods have recently been developed. However, analysis of an adult $W$. fuliginea specimen was required to confirm the tentative identification of a $W$. fuliginea larva collected from Southland. No adult $W$. fuliginea have been collected in the last twenty years so DNA was extracted from voucher specimens of 33-year-old dried W. fuliginea adults held by the New Zealand Arthropod Collection. A 1,035 bp sequence of the cytochrome oxidase I gene for each of the two museum $W$. fuliginea voucher moths was generated and proved identical to the sequence from the Southland larva. A new method for confirming the identification of porina specimens is available as a result of this work.
\end{abstract}

Keywords Porina, museum specimen, insect identification.

\section{INTRODUCTION}

Caterpillars of the endemic genus Wiseana Viette (Lepidoptera: Hepialidae), commonly known as porina, occupy niches from alpine regions to lowland plains (Brown et al. 2000) and have been shown to feed on a variety of plants (Atijegbie et al. 2016, Ehau-Taumanu et al. 2016). They are significant pests of improved pasture, in which both ryegrass (Lolium spp.) and white clover (Trifolium repens) are attacked, throughout much of New Zealand (Barratt et al. 1990) costing farmers up to \$500M p.a. (C. M. Ferguson, unpublished). With taxonomic expertise, moths may be identified to species level using morphological criteria such as wing-scale shape, antennal-segment shape and examination of dissected genitalia (Dugdale 1994). However, identification of the pasturedefoliating caterpillars to species level using morphological features is impossible. As a result, porina have been historically treated as a single pest complex yet inter-specific differences among porina are known to impact on the efficacy of some porina management strategies. The inability to distinguish between porina species from larval specimens has impeded the development and optimisation of sustainable management options (Ferguson 2000). 
Seven Wiseana species are currently recognised based on adult morphology: W. cervinata (Walker), W.copularis(Meyrick), W.fuliginea(Butler), W.jocosa (Meyrick), W. mimica (Philpott), W. signata (Walker) and W. umbraculata (Guenée) (Dugdale 1994; Nielsen etal.2000).Allozymeand phylogenetic studies have already revealed sub-populations or new haplotypes within three of the species (W. cervinata, W. copularis, W. signata), tentatively associated with geographic boundaries (MacArthur 1986; Herbert 1995; Brown et al. 1999a). A recent study showed this geographic association held true for haplotypes of $W$. cervinata and W. signata, however the supposed 'northern' haplotype of W. copularis was found not only in the North Island but also the South Island and Chatham Islands of New Zealand (Richards et al. 2017).

Mitochondrial sequences (526 bp) that spanned the 3' cytochrome oxidase I (COI) and 5 ' COII genes for one voucher adult specimen per species and haplotype were published by Brown et al. (1999a). The first non-sequencing based molecular tool for porina species identification used restriction fragment length polymorphisms (RFLPs) of an amplified 2,200 bp mitochondrial COI and II gene product (Brown et al. 1999b). This method proved impracticable for field studies as the restriction profiles were complex with low size variability, and the level of genetic variation within this mitochondrial region was not known. Therefore, a study was recently undertaken to develop fast and easy non-sequencing tools for porina species identification (Richards et al. 2017). This study described and validated two new, molecular-based identification methods focused on sequencing a $1,718 \mathrm{bp}$ mitochondrial region that covered the whole COI gene and the 5' COII gene in porina specimens collected from broadly separated regions throughout New Zealand. As part of this study, a single larva was fortuitously collected from a pasture at Mararoa Downs, Southland, which was tentatively identified as W. fuliginea. This tentative identification was based on the $1,718 \mathrm{bp}$ sequence for its mitochondrial COI and COII genes being more than $1 \%$ different to voucher specimens for the other known porina species (Richards et al. 2017) and the smaller 526 bp 3' COI and 5' COII sequence being identical to the $W$. fuliginea voucher specimen described by Brown et al. (1999a). However, this 526 bp region varied by only 1 bp for $W$. fuliginea and $W$. mimica so it is not a reliable method for differentiating between these two species. Intraspecific variation is prevalent within the mitochondrial COI and COII of porina species. For example, seven $W$. mimica specimens collected from Otago and Southland varied by 1 to 2 bp within the aforementioned 526 bp region (Richards et al. 2017).

To confirm the species assignment of the unusual larva, it was necessary to source and then sequence the larger $1,718 \mathrm{bp}$ COI and COII region from a voucher specimen of a $W$. fuliginea adult. Unfortunately, the voucher specimens collected by Brown et al. (1999a) could not be located. Pasturefocused porina investigations have been undertaken for the past twenty years and moths have been collected throughout the complete flying seasons by light trapping at several South and North Island sites. Collected specimens have been identified to species level using Dugdale's (1994) taxonomic key but no adults that could be definitively identified as W. fuliginea have been detected. In January 2017, light traps were erected on the Southland farm where the tentative $W$. fuliginea larva was collected the previous winter, but again, no W. fuliginea adults were captured. The authors were, therefore, delighted to be granted access to two voucher specimens of $W$. fuliginea adults collected and archived at the New Zealand Arthropod Collection (NZAC) by MacArthur (1986).

Hundsdoerfer and Kitching (2017) made use of archived voucher specimens to analyse the degree of divergence between 100-year-old specimens of a rare hawkmoth species and other readily available hawkmoth species. The current paper describes how the tentative identification of the $W$. fuliginea larva by Richards et al. (2017) was confirmed by successfully extracting DNA and sequencing 1,035 bp of the mitochondrial COI gene from museumarchived $W$. fuliginea adult voucher pin specimens. This work was conducted using established guidelines for working with historic specimens (Wandeler et al. 2007). 


\section{MATERIALS AND METHODS Specimen collection}

Two voucher moths for male $W$. fuliginea were sourced from the NZAC curated by Landcare Research (Auckland). The moths were collected by Gordon MacArthur (R177, 26 Oct 1984; R178, 29 Oct 1984) from a pasture trial site located in Invermay (Dunedin, Otago) and submitted to the NZAC as pin specimens in 1986 as part of an unpublished Master's thesis undertaken at Victoria University of Wellington.

\section{DNA extraction}

DNA was extracted from two legs for each NZAC voucher moth, using the Genomic DNA Mini Kit Tissue (Geneaid ${ }^{\mathrm{TM}}$, Taiwan) following manufacturer's specifications. Proteinase K digestion was performed for one hour at $60^{\circ} \mathrm{C}$. Final elution was performed using two sequential washes of $100 \mu \mathrm{L}$ elution buffer, yielding a final volume of $200 \mu \mathrm{L}$ for each specimen. Genomic DNA was stored short-term in the fridge $\left(4-8^{\circ} \mathrm{C}\right)$ or long-term in the freezer $\left(-5\right.$ to $\left.-80^{\circ} \mathrm{C}\right)$.

\section{Amplification and primer design}

PCR reactions contained $i$-StarTaq ${ }^{\mathrm{TM}}$ DNA polymerase (iNtRON Biotechnology, South Korea) at approx. 1 unit/20 $\mu \mathrm{L}$ PCR, $2 \mathrm{mM}$ $\mathrm{MgCl}_{2}, \quad 0.2 \mathrm{mM}$ dNTPs, $0.2 \mu \mathrm{M}$ primers (Integrated DNA Technologies, Singapore) and $1 \mu \mathrm{L}$ template DNA at ca. 1 ng per $20 \mu \mathrm{L}$ of PCR reaction. Cycling conditions depended on the primer pair, but in general started at $95^{\circ} \mathrm{C}$ for 2 min, followed by 40 cycles of $95^{\circ} \mathrm{C}$ for $30 \mathrm{sec}, 45$ to $50^{\circ} \mathrm{C}$ for $30 \mathrm{sec}$ and $72^{\circ} \mathrm{C}$ for 30 to $45 \mathrm{sec}$; the final step was $5 \mathrm{~min}$ at $72^{\circ} \mathrm{C}$. All PCR runs included a template-free reaction as a negative control. The primers used to amplify the 5' COI gene barcode region (Folmer et al. 1994), mid COI (Richards et al. 2017) and 3' COI/ 5' COII gene regions (Brown et al. 1994) are listed in Table 1. Mitochondrial sequences, spanning the COI and COII genes (Richards et al. 2017 KY353012KY353086), for all porina species including the tentative W. fuliginea larva (KY353038) were aligned using the programme MUSCLE (Edgar 2004). A range of primers were then designed to border short regions (ca. 100-400 bp) containing species-specific polymorphisms. Only sequences for the primer pairs that worked for the NZAC voucher specimens are listed in Table 1. PCR products and $100 \mathrm{bp}$ ladder (DNA Marker 1, A\&A Biotechnology, Poland) were run on $1 \%$ agarose gels containing RedSafe ${ }^{\mathrm{TM}}$ (iNtRON Biotechnology, South Korea), in $0.5 \times$ UltraPure $^{\mathrm{TM}}$ TBE Buffer (Invitrogen, USA).

\section{Sequencing and alignment}

Sanger sequencing (BigDye ${ }^{\circledR} \mathrm{V}$ 3.1, Applied Biosystems) was conducted at Macrogen (Korea). For each NZAC voucher moth, the overlapping short mitochondrial sequences were trimmed and aligned using Geneious version 8.1.5 (http://www.geneious.com, Kearse et al. 2012) to create one sequence and then compared with previously published sequences (Brown et al. 1999a AF098332-AF098359; Richards et al. 2017 KY353012-KY353086). Multiple alignments of the nucleotide sequences were generated using the program MUSCLE (Edgar 2004).

\section{RESULTS}

No products were amplified from the 33-yearold NZAC W. fuliginea voucher specimens using the previously described mitochondrial COI and COII primer sets (Folmer et al. 1994, Brown et al. 1994; Richards et al. 2017). However, amplification of shorter regions within the COI gene using primers designed in this study (Table 1) was successful, and the resulting sequences were aligned to produce a 1,035 bp sequence that was identical to the sequence from the 'tentative' $W$. fuliginea Southland larva (KY353038, Richards et al. 2017). The sequences from the $W$. fuliginea museum voucher specimens, InvR177_Otago and InvR178_Otago, were deposited in Genbank under accession numbers MF069505 and MF069506, respectively.

\section{DISCUSSION}

Light trapping at several South and North Island sites over twenty years has not yielded a single adult identified as $W$. fuliginea. This result may reflect that the morphological characters 
Table 1 Details for PCR primer pairs based in the porina mitochondrial cytochrome oxidase I (COI) gene

\begin{tabular}{|c|c|c|c|c|}
\hline $\begin{array}{l}\text { Primer } \\
\text { name }^{1}\end{array}$ & Primer sequence ( $5^{\prime}$ to $\left.3^{\prime}\right)$ & $\begin{array}{l}\text { Product } \\
\text { size (bp) }\end{array}$ & $\begin{array}{l}\text { Target } \\
\text { region }\end{array}$ & Reference \\
\hline LCO1490 & GGTCAACAAATCATAAAGATATTGG & & & Folmer et al. 1994 \\
\hline HCO1764 & GCATTTCCTCGTTTAAATA & 274 & $5^{\prime} \mathrm{COI}$ & this study \\
\hline LCO1635 & GTAATTGTAACAGCACATGC & & & this study \\
\hline HCO1879 & ССТTTATCYTCTAATATTGC & 244 & 5' COI & this study \\
\hline LCO1812 & AGAAGAATTGTAGAAAATGG & & & this study \\
\hline $\mathrm{HCO} 2198$ & TAAACTTCAGGGTGACCAAAAAATCA & 386 & 5' COI & Folmer et al. 1994 \\
\hline LCO2184 & GGTCATCCTGAAGTATATAT & & & this study \\
\hline $\mathrm{HCO} 2374$ & GGTATAGATGTAGATACYCG & 190 & 5' COI & this study \\
\hline LCO2355 & GGTATAGATGTAGATACYCG & & & Richards et al. 2017 \\
\hline $\mathrm{HCO} 2563$ & GCTAACTCTTCAATTGATAT & 208 & $5^{\prime} \mathrm{COI}$ & this study \\
\hline LCO 1490 & GGTCAACAAATCATAAAGATATTGG & & & Folmer et al. 1994 \\
\hline $\mathrm{HCO} 2198$ & TAAACTTCAGGGTGACCAAAAAATCA & 708 & Barcode & Folmer et al. 1994 \\
\hline LCO2069 & ACCTGTATTAGCRGGWGCTA & & & Richards et al. 2017 \\
\hline HCO2915 & CGTTTTCTAATTATTGATTCTC & 846 & mid COI & Richards et al. 2017 \\
\hline S2792 & ATACCTCGACGTTATTCAGA & & & Brown et al. 1994 \\
\hline $\mathrm{HCO} 3306$ & GGTAATTGCAGGTAAGATTGT & 528 & 3' COI to & Brown et al. 1994 \\
\hline A3389 & TCATAAGTTCARTATCATTG & 597 & 5’ COII & Richards et al. 2017 \\
\hline
\end{tabular}

${ }^{1}$ New primers were named using the system described by Folmer et al. (1994) where L and H refer to light and heavy DNA strands, CO refers to cytochrome oxidase, and the numbers refer to the position of the Drosophila yakuba 5' nucleotide.

described by Dugdale (1994) to distinguish W. fuliginea from other porina species are unreliable and/or that this species is rare in pasture environments. Identifying porina species using morphological characters alone is extremely difficult even for an experienced taxonomist. For example, moths collected by B. Brown (23 Oct 1997, Birdling's Flat, Canterbury) and C. Ferguson (22 Nov 1997, Waimahaka, Southland) and determined by J. Dugdale to be $W$. fuliginea, have been subsequently shown to be W. cervinata and W. jocosa, respectively using molecular technologies (N. Richards unpublished). Barratt et al. (1990) reported $W$. fuliginea as being associated with wet lowlands, and it appears to be the least widespread of the porina species being collected from only three locations nationwide (Dugdale 1994). The pasture from which our tentative $W$. fuliginea larva specimen was collected was adjacent to a native bush margin and associated patches of grassland in a high rainfall area. It is possible that such a habitat is a natural environment for W. fuliginea and that its apparent rarity in pastoral environments may be due to our inability to identify larvae until now.

Amplification of the DNA from the museum voucher moths with the same primers used by Brown et al. (1999a) and Richards et al. (2017) was unsuccessful, most likely due to degradation of the DNA by endogenous nuclease activity and hydrolytic damage (Wandeler et al. 2007). This was overcome by designing a series of primers that amplified smaller overlapping regions of the porina mitochondrial COI gene $(<400 \mathrm{bp}$, Table 1), similar to the method used by Hundsdoerfer and Kitching (2017) to successfully retrieve mitochondrial COI and COII sequences from 100-year-old museum hawkmoth specimens. 
This study successfully confirmed that the larva collected from Te Anau and tentatively identified as $W$. fuliginea was the elusive $W$. fuliginea species. More importantly, a 1,718 bp region of the mitochondrial COI and COII genes is now available for all porina species and haplotypes thereby completing the Richards et al. (2017) study that developed a molecular identification technique for accurate determination of porina moths and larvae to species and sub species level. Indeed, these new molecular porina identification tools have already been used in several field-based studies. Ferguson et al. (2016) reported that the main flight time in the Manawatu for a W. copularis northern haplotype occurred during March/ April, much later in the southern hemisphere growing season than traditional flights times of October and January displayed in other regions. Further, it was shown that although other porina species were collected during these flights, only $W$. copularis northern haplotype larvae were found in pastures (Richards et al.2017). This result highlights the fact that generalised porina flight periods are not accurate indicators of localised activity, and that species composition, regional differences in species composition and timing of caterpillar development need to be considered for successful porina management strategies. A related three-year study is the first to present data on porina flight activity followed up with the species composition of porina larvae collected from the same locations (Mansfield et al. 2017). Again, the results of that study illustrated that the species composition of porina moth flights, does not necessarily match the composition of larval populations in pasture. The work conducted by Ehau-Taumaunu (2017) investigated the species distribution and bacterial microbiota of porina larvae collected from five pasture and three native habitats across New Zealand was able to determine the species of larvae collected from both habitats and showed that the composition varied with habitat.

It is now possible to accurately determine which porina species are pests of agricultural significance and to overcome the restrictions of dealing with a pest complex. Ecological studies can be carried out with confidence and porina research can be brought into the twenty-first century.

\section{ACKNOWLEDGEMENTS}

Our thanks to Gordon MacArthur for archiving adult voucher specimens for porina species during his $\mathrm{PhD}$ project at Victoria University of Wellington, to Dr Robert Hoare (Head Curator, Lepidoptera, NZAC) for granting access to the $W$. fuliginea voucher specimens without which this study could not be completed and to Dr Sean Marshall (AgResearch, Lincoln) for suggesting we try shorter regions when our first attempts to amplify the mitochondrial COI and COII genes from the museum specimens failed. We appreciated the feedback from AgResearch internal reviewers (Drs. Sarah Mansfield and Sean Marshall), and New Zealand Plant Protection reviewers (Dr Ruth Falshaw and an anonymous reviewer). This work was supported by MBIE under the Ecosystems Bioprotection programme LINX0804.

\section{REFERENCES}

Atijegbe SR, Mansfield S, Rostás M, Worner S, Ferguson CM 2016. Growth rate, survival and preference of porina (Wiseana spp) to selected grasses. New Zealand Plant Protection 69: 326.

Barratt BIP, van Toor RF, Ferguson CM, Stewart KM 1990. Grass grub and porina in Otago and Southland: a guide to management and control. MAF Technology, Mosgiel, New Zealand.

Brown B, Emberson RM, Paterson AM 1999a. Phylogeny of "Oxycanus" lineages of hepialid moths from New Zealand inferred from sequence variation in the mtDNA COI and II gene regions. Molecular Phylogenetics and Evolution 13: 463-473.

Brown B, Emberson RM, Paterson AM 1999b. Mitochondrial COI and II provide useful markers for Wiseana (Lepidoptera: Hepialidae) species identification. Bulletin of Entomological Research 89: 287-293.

Brown B, Emberson RM, Paterson AM 2000. Phylogenetic relationships within the genus Wiseana (Lepidoptera: Hepialidae). New Zealand Journal of Zoology 27: 1-14. 
Brown JM, Pellmyr O, Thompson JN, Harrison RG 1994. Phylogeny of Greya (Lepidoptera: Prodoxidae), based on nucleotide sequence variation in mitochondrial cytochrome oxidase I and II: congruence with morphological data. Molecular Biology and Evolution 11: 128-141.

Dugdale JS 1994. Hepialidae (Insecta: Lepidoptera). Manaaki Whenua Press, Lincoln, New Zealand.

Edgar RC 2004. MUSCLE: Multiple sequence alignment with high accuracy and high throughput. Nucleic Acids Research 32: 17921797.

Ehau-Taumaunu H, Marshall SDG, Ferguson CM, Mark-Shadbolt M, MacDiarmid RM, O'Callaghan M 2016. A sweet potato story: the likelihood of porina feeding on kumara. New Zealand Plant Protection 69: 324.

Ehau-Taumaunu H 2017. Uncovering microbiota profiles and traditional Máori host plants of Wiseana spp. in New Zealand. Thesis submitted for Masters of Science, University of Auckland.

Ferguson CM 2000. Susceptibility of Wiseana species to diflubenzuron and implications for field applications. New Zealand Plant Protection 53: 430-435.

Ferguson CM, Gee-Taylor MA, Richards NK 2016. February/March moth flights in Manawatu have important implications for porina management. New Zealand Plant Protection 69: 326.

Folmer O, Black M, Hoeh W, Lutz R, Vrijenhoek $R$ 1994. DNA primers for amplification of mitochondrial cytochrome c oxidase subunit I from diverse metazoan invertebrates. Molecular Marine Biology and Biotechnology 3: 294-299.

Herbert JM 1995. Biochemical identification of Wiseana larvae and implications for pest control. Unpublished Ph.D. thesis, Victoria University of Wellington, Wellington, New Zealand.
Hundsdoerfer AK, Kitching IJ 2017. Historic DNA for taxonomy and conservation: A casestudy of a century-old Hawaiian hawkmoth type (Lepidoptera: Sphingidae). PLOS One doi.org/10.1371/journal.pone.0173255.

Kearse M, Moir R, Wilson A, Stones-Havas S, Cheung M, Sturrock S, Buxton S, Cooper A, Markowitz S, Duran C, Thierer T, Ashton B, Meintjes P, Drummond A 2012. Geneious Basic: an integrated and extendable desktop software platform for the organization and analysis of sequence data. Bioinformatics 28: 1647-1649.

MacArthur G 1986. An electrophoretic contribution to the systematics of the genus Wiseana Viette (Lepidoptera: Hepialidae). Unpublished Masters thesis, Victoria University of Wellington, Wellington, New Zealand.

Mansfield S, Townsend RJ, Ferguson CM, Richards NK, Marshall SDG 2017. Porina flight activity and larval distribution in pastures on the West Coast of the South Island. [Poster]. New Zealand Plant Protection 70: 327.

Nielsen ES, Robinson GS, Wagner DL 2000. Ghost-moths of the world: a global inventory and bibliography of the Exoporia (Mnesarchaeoidea and Hepialoidea) (Lepidoptera). Journal of Natural History 34: 823-878.

Richards NK, Mansfield S, Townsend RJ, Ferguson CM 2017. Genetic variation within species and haplotypes of the Wiseana (Lepidoptera: Hepialidae) complex and development of non-sequenced based identification tools to aid field studies. Pest Management Science. doi:10.1002/ps.4620.

Wandeler P, Hoeck PEA, Keller LF 2007. Back to the future: museum specimens in population genetics. TRENDS in Ecology and Evolution 22: 634-642. 